\title{
A cobertura esportiva dos Jogos Olímpicos de Londres 2012: a tematização do "doping” no portal de notícias G1
}

CDD. 20.ed. 796.022

796.48

\author{
Paulo Rodrigo Pedroso da SILVA* \\ Carlos Henrique de Vasconcelos RIBEIRO* \\ Lamartine Pereira DaCOSTA*
}

\section{Resumo}

0 "doping" no esporte gera questões de interesse constante na mídia, sobretudo durante a realização de Jogos Olímpicos (JO). Especialmente nos casos de "doping" envolvendo os grandes nomes do esporte olímpico internacional, como Ben Johnson nos J0 de Seul 1988 e Marion Jones em Sydney 2000, os quais arruinaram suas reputações da noite para o dia. 0 objetivo deste trabalho é investigar as notícias "online" a respeito de "doping" publicadas durante os Jogos Olimpicos de Londres 2012 (JOL) em um grande portal de notícias brasileiro o G1. Para isto, foi selecionado e classificado o conteúdo de todo o material publicado com as palavras-chave: "doping" e jogos olímpicos de Londres, durante o período de 25 de julho a 13 de agosto de 2012. Verificamos um total de 191 reportagens das quais foram incluídas na análise 145, 54 delas foram encontradas no Extra Online, seguidas de 37 no site do Globo Esporte, 23 no site do G1, 22 no Jornal 0 Globo e nove na Revista Época. Em cima deste material, uma leitura em profundidade centrada na análise de conteúdo foi realizada. Os resultados desta análise indicaram duas categorias de consenso: a) as desconfianças em torno do desempenho dos atletas; b) as punições destinadas aos atletas com exames positivos. Os conteúdos analisados nesse portal apresentam os atletas com o "doping" positivo como trapaceiros e a Agência Mundial Antidoping (AMA) como uma espécie de polícia internacional que está em permanente guerra contra o "doping". Tal fato parece semelhante com a guerra às drogas, em vigília constante sobre os resultados esportivos individuais dos atletas.

Palavras-chave: "Doping"; Esportes; Imprensa; Atleta.

\section{Introdução}

Circulam pelos meios de comunicação conteúdos diversos sobre o uso de substâncias proibidas com a finalidade de melhorar o rendimento atlético ("doping"a), fazendo com que esta temática esteja sempre na pauta midiática, tendo maior ou menor destaque, dependendo do atleta que foi pego (teste positivo), da importância no meio esportivo, da capacidade de causar impacto e reverberar esta notícia por alguns dias ${ }^{1}$.

As notícias de "doping" variam desde a culpabilização exclusiva do atleta até o apontamento de que o sistema no qual este indivíduo é inserido está contaminado, se enfatiza ainda que o atleta é um problema da própria estrutura esportiva na medida em que esta se profissionalizou ${ }^{2-4}$.

Quando algum atleta de elite é flagrado, por exemplo, em um teste positivo de "doping", há em consequência disto uma interpretação dos órgãos controladores de que as tomadas de decisão devem ser vistas como única e exclusivamente individuais (atleta), não levando em conta as redes entre atletas, técnicos, dirigentes, médicos, familiares e patrocinadores.

$\mathrm{Na}$ complexidade destas questóes é que situamos o nosso campo de estudos, em conteúdos que por diversas vezes são tratados pelos meios de comunicação de forma simplista, grosso modo, e de maneira a cogitar que tudo é uma questão (moralista) de "estar limpo" ou contaminado, ou como conceituou a antropóloga Mary Douglas citada por Perera e GLeYSE ${ }^{6}$ de estar puro ou impuro, dividindo aqueles que merecem nossa admiração e aqueles que apenas representam a vergonha.

Independente das questôes que cercam as escolhas individuais ou da permissividade coletiva nos 
interessa investigar como a mídia brasileira aborda esta temática durante a realização dos Jogos Olímpicos de Londres 2012. Para tanto, nós focamos em portais eletrônicos de informação, nos meios de comunicação que durante a realização dos jogos alimentaram o grande público com conteúdos relacionados a este assunto. Optamos pelo portal eletrônico ao jornal impresso, visto que entre um e o outro, muitas matérias são reduzidas ou ainda nem são colocadas na pauta por uma questão de espaço.

Levando em consideração a obra clássica de WolF ${ }^{7}$ os estudos "mass media" atendem as diversas dimensões e ressaltam a importância de problematizar questôes ligadas ao setor industrial específico (ex. Jogos Olímpicos), além de fazer parte do cotidiano das pessoas que investem parte de seu tempo consumindo estes produtos.

A construção da realidade na qual se quer compreender está pautada na ideia geral de que os confrontos, os interesses e as ideologias se sobrepõem, fazendo desta área de estudo um mosaico de teorias, metodologias e análises na construção do objeto na perspectiva dos "cultural studies", ou seja, que está relacionado ao conceito de cultura que aqui estão pautados sobre:

... os significados e os valores, que surgem e se difundem nas classes e nos grupos sociais, quer as práticas efectivas através das quais esses valores e esses significados se exprimem e nas quais estão contidos. Relativamente a tais definições e modos de vida - entendidos como estruturas colectivas - os mass media desempenham uma função importante, na medida em que agem como elementos activos dessas mesmas estruturas ${ }^{7}$.

Além disto, desejamos compreender como estes conteúdos ganham espaço na mídia e como as questões de "doping" na nossa sociedade ganham relevância, mesmo que tratados de forma ágil para informar antes da concorrência. É provável que este perfil de profissionais do jornalismo redija suas matérias para o grande público procurando repercutir de forma polêmica seu material, sobretudo se a matéria redigida é sobre o rendimento de um atleta de grande visibilidade. Inferimos que independente da mídia ser impressa ou virtual, ainda assim é mídia e como tal opera com elementos dicotômicos e simplistas, facilmente identificados pelos seus leitores rotineiros ${ }^{8}$.

Sendo assim, o objetivo desta pesquisa será analisar os conteúdos sobre "doping" publicado no portal de notícias G1 durante a realização os JOL. A partir da problematização descrita acima, queremos investigar como o portal de notícias G1 tratou, na cobertura jornalística, a questão do "doping" durante a realização dos Jogos Olímpicos de Londres 2012.

\section{Metodologia da constituição do "corpus" de análise}

A coleta de material para a nossa pesquisa se deu durante o Calendário Olímpico e a realização dos Jogos Olímpicos de Londres, período compreendido entre os dias 25 de julho a 13 de agosto de 2012. Na primeira parte foi feita uma busca dentro do G1. Escolhemos este portal de informações, pois é nele que se concentram as notícias vinculadas conteúdos jornalísticos de grande visibilidade e audiência. Segundo dados do Alexa Internet ${ }^{\mathrm{b}}$ (serviços de internet pertencente à Amazon que é capaz de medir quantos usuários visitam um site específico) este portal ocupa a sétima posição de acesso no Brasil, atrás apenas do Facebook, Google Brasil, Google, YouTube, Universo Online e Windows Live. Em relação ao público do G1, a maioria dos leitores é composta de homens na faixa etária de 25 a 34 anos que possuem formação de nível superior ou acima e que acessam este portal normalmente do ambiente de trabalho.

Procuramos por notícias que continham as seguintes palavras-chave: "doping" e jogos olímpicos de Londres
2012. Em um segundo momento foi realizado uma leitura abrangente de todas as matérias encontradas. Analisando todos os títulos e subtítulos e os conteúdos em busca das "palavras-chave" pesquisadas dentro do contexto dos Jogos Olímpicos de Londres.

Foram encontradas no período entre os dias 25 de julho e 13 de agosto o total de 191 reportagens no G1. Destas reportagens foram excluídas inicialmente 46, pois tratavam de notícias sobre "doping" em competiçôes esportivas fora do escopo dessa pesquisa, por exemplo: o evento de lutas UFC e o campeonato brasileiro de futebol de 2012 .

Das 145 reportagens incluídas, 54 foram encontradas no Extra Online, 37 no site do Globo Esporte, 23 no site do G1, 22 no Jornal O Globo e nove na Revista Época.

$\mathrm{Na}$ etapa seguinte realizamos uma leitura em profundidade de todas as matérias (145) com o propósito de selecionar, classificar e agrupar as informações em um quadro. Com as palavras-chave: 
nos seguintes pontos: a) data; b) site; c) título; d) citaçôes do "doping"; e) atletas citados; f) esportes citados; g) substâncias referidas; h) desfecho; i) "link". Essa observação consistiu em verificar o frequente uso das seguintes palavras: a) esporte; b) "antidoping"; c) "doping"; d) substâncias proibidas; e) atletas; f) Jogos Olímpicos; g) olimpíadas; h) trapaceiros; i) banido (a); j) suspeita; expulso (a).

Em um quarto momento os pesquisadores realizaram a análise temática adotada para o campo da saúde coletiva, centrada na análise de conteúdo de Laurence BARDIN de 1970 por MINAYO9 . Será esse procedimento que utilizaremos a seguir, buscando atingir os significados no que está escrito, mapeado ou simbolicamente explicitado nos conteúdos manifestos e/ou latentes nos textos selecionados. Buscamos neste contexto compreender como são reproduzidas as ideias, as intencionalidades sobre uma temática transformada em notícias cotidianas, pautadas por um portal de notícias online, o que mantém em seu conteúdo, quais são vozes que são captadas na diversidade de opiniōes, comentários e impressões.
Tal compreensão reforça a ideia central de que não há um único projeto editorial, mesmo que investiguemos este único portal. O que está posto a partir das próximas páginas é mostrar esta interdiscursividade, esta polifonia ${ }^{10}$.

As unidades de contexto que foram reunidas se formaram a partir do aprofundamento das matérias. A partir deste momento percebemos que existiam duas grandes formas que se constituíram nossas análises. A primeira estava relacionada ao fato de um atleta ter sido pego pelo teste a "antidoping". Ou seja, nossa primeira categoria se formou a partir das análises dos atletas que foram expulsos, que as delegações tiveram que se pronunciar ou ainda dos órgãos de controle se posicionado sobre o resultado do teste.

A segunda categoria de análise foi sendo reunida a partir das unidades de registro que continham a marca da explicação, da dúvida, da desconfiança sobre determinado resultado de um atleta. Dependendo da nacionalidade, gênero, esporte, fama e ainda do resultado feito, das desconfianças que estavam marcadas nos conteúdos das reportagens.

\section{Análise dos resultados}

Inicialmente abordaremos as frequências com o objetivo de trazer uma visão abrangente dos achados da primeira parte. Em relação à quantidade de reportagens produzidas pelo portal G1 sobre a temática do "doping” nos Jogos Olímpicos de Londres 2012 por dia, verificamos o maior volume no dia de 4 de agosto de 2012. Veja na FIGURA 1.

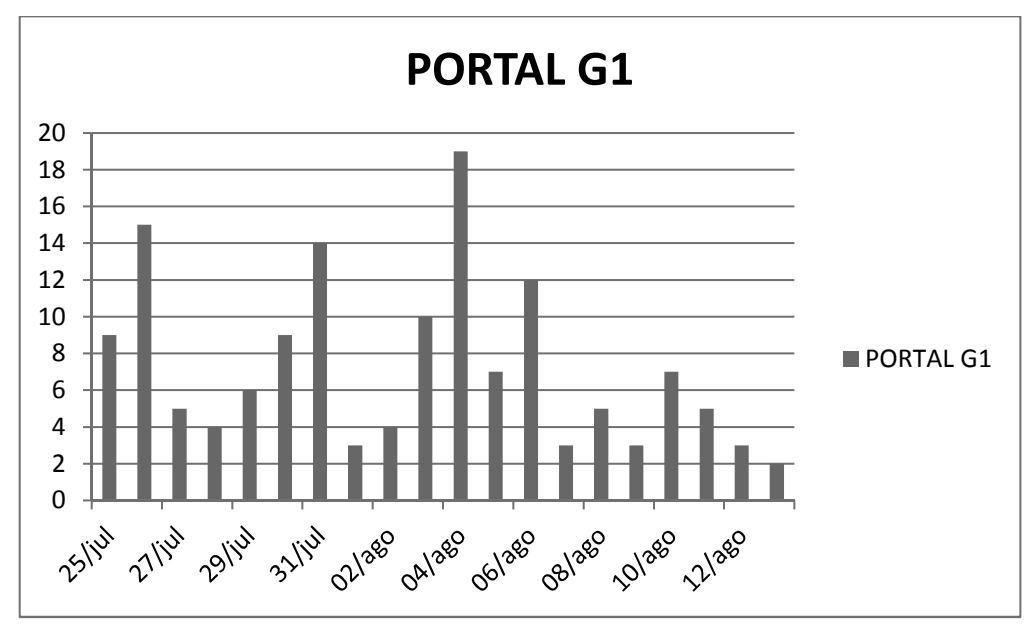

FIGURA 1 - Número total de matérias publicadas por dia sobre "doping" segundo o portal G1 entre os dias 25/07/12 e 13/o8/12.

Outro dado relevante nesta pesquisa "online" foi relativo aos títulos das reportagens que em grande parte apresentaram o uso exagerado de determinadas expressões de apelo emocional, como: exclusão, expulsão, eliminado, banimento, "flagra". $\mathrm{Na}$ leitura destas expressões verificamos na informação 
o compromisso de transmitir aos leitores a eficiência e rapidez de um sistema "antidoping" infalível nos Jogos Olímpicos de Londres. Por exemplo: Londres 2012: COI confirma exclusão de atleta da Albânia por "doping" "11; Velocista são-cristovense é eliminada por admitir uso de $\operatorname{droga}^{12}$; Corredor marroquino Laalou é flagrado no "doping" ${ }^{13}$; Ciclista russa é expulsa dos Jogos Olímpicos de Londres por "doping"14; Italiano campeão olímpico de marcha é excluído da Olimpíada por "doping"15; Corredora síria é $11^{\mathrm{a}}$ atleta banida dos Jogos por "doping"16.

Verificamos ainda que há nos títulos a intenção de mostrar que o "doping" "per si" não pode prejudicar o espetáculo esportivo e que cada caso de "doping" tende a prejudicar a imagem geral do megaevento. $\mathrm{O}$ "doping", portanto, teria a capacidade de manchar este grande espetáculo, fazendo disto uma notícia maior até mesmo do que o espetáculo em si? Por exemplo: Londres tem terceiro caso de "doping" em dois dias ${ }^{17}$; IAAF confirma nove punições por "doping" às vésperas das Olimpíadas ${ }^{18}$.

Em nossa análise seguinte dividimos as reportagens em duas grandes categorias, a saber, a primeira é composta de reportagens que tratam dos casos de "doping" individualmente, são as reportagens que tratam dos casos confirmados, dos atletas "pegos" pelos exames e daqueles casos dos atletas famosos com seus desempenhos duvidosos, que por terem tido destaque em suas competições, acabaram sofrendo pressões de discursos desconfiados.

A segunda, análise identificou que a atitude repressiva, tende a criar polêmicas em torno dos casos considerados "positivos" para testes de "doping". Neste momento é dado destaque às autoridades esportivas e aos que falam do lugar social de especialistas no assunto, tais como comentaristas, técnicos e ex-atletas. Nestas reportagens compreendemos que o caráter policialesco toma forma e as instâncias de controle precisam ser ouvidas para confirmar, discutir e banir a partir de uma política de "tolerância zero" quanto ao uso destas substâncias.

\section{Recordes e desconfianças: ele (a) realmente fez isso?}

Uma espécie de gatilho é acionada para a produção de conteúdo e opinião na mídia de plantão (ex. jornalistas, comentaristas e especialistas) quando os atletas olímpicos apresentam resultados extraordinários e recordes. Sobretudo, os resultados que levantam dúvidas quanto à integridade dos atletas que por alguma razão ganharam espaço e notoriedade rapidamente em um evento de magnitude olímpica.

Especialmente os atletas provenientes dos esportes individuais, que fazem o espetáculo esportivo mais impactante na mídia. Diferentes dos esportes coletivos, os esportes individuais permitem que a relação entre o esporte tomado como pauta pela mídia seja diretamente relacionada com o melhor atleta da modalidade. Além disso, sem um ídolo, um ícone capaz de chamar a atenção de público e consequentemente de patrocinadores, um esporte não se desenvolve ${ }^{19}$.

Os maiores destaques das reportagens estudadas foram os atletas que se consagraram nos JOL, mas há de se destacar que em grande maioria das matérias estudadas vinham junto com poréns, ou seja, a visibilidade dada era feita com ressalvas, até que algo fosse provado contra este (a) atleta ${ }^{20 c}$.

Somente a nadadora chinesa Ye Shiwen de 16 anos de idade recebeu a atenção em nove matérias. Se somarmos as quatro relacionadas ao velocista Usain Bolt teremos 13 só sobre estes atletas que individualmente conseguiram feitos importantes para suas carreiras e para os países que representaram. Contudo, seus desempenhos foram tomados com ressalvas. Por exemplo, ao mesmo tempo em que surpreendem as matérias jornalísticas apoiadas em depoimentos de treinadores e comentários esportivos, elas passavam a questionar os resultados, gerando assim dúvidas sobre a capacidade destes atletas. Conseguir nadar mais rápido que um homem no mesmo tipo de prova, como no caso da nadadora chinesa, ou de sagrar-se bicampeão em duas provas de velocidade, como no caso do atleta jamaicano, se transformou em algo espetacular, porém duvidoso. Selecionamos abaixo os seguintes trechos para exemplificar essa análise:

'Isso é realmente injusto e sem fundamento', disse

Liu. Há indivíduos e jornalistas que estão acusando, sem fundamento, os nossos atletas chineses. 'Essas pessoas deveriam respeitar a dignidade e reputação dos esportistas ${ }^{20 d}$ (grifo nosso).

O jamaicano disse que fica longe de drogas e suplementos alimentares para evitar qualquer problema nesse sentido. 'Eu estou ciente que, se houvesse algum escândalo de drogas me envolvendo, seria o fim do atletismo. Isso não irá acontecer', afirmou. Bolt está ciente da sua responsabilidade por recuperar a credibilidade da prova, presente desde a Olimpíada de 1896, a primeira da era moderna. E a confirmação do seu reinado em Londres serve para confirmar de vez essa nova era. Antes de Bolt, 
os 100 metros rasos haviam se tornado um sinônimo de doping ${ }^{21}$ (grifo nosso).

A desconfiança precede a glória do atleta, mesmo que imediatamente após a competição sejam feitos controles de "doping". Neste sentido, contribui bastante o fato de que o material recolhido destes atletas deve ficar armazenado por pelo menos oito anos, tal como no caso do ciclista Tyler Hamilton $^{\mathrm{e}}$. Estamos diante da compreensão de que o limite humano para a conquista de novos recordes está se aproximando daquilo que é ou não eternamente legitimo. Dentro desta colocação seria possível aventarmos que as "vitórias" - desempenho formidável e controle de "doping" negativo - do atleta de hoje poderão ser as "derrotas" - perda de medalha e controle de "doping" positivo - do amanhã.

Neste sentido, o esporte espetáculo deverá se apoiar em julgamentos não mais nas habilidades e no bom senso dos humanos que interpretam o vencedor, mas nas máquinas que comprovarão qual o tempo real do atleta, quem de fato chegará primeiro ou ainda, quem estava ou estará realmente limpo. A desconfiança tomará conta da torcida até que se prove o contrário.

Assim como todo e qualquer elemento que ajude a mídia a produzir notícias sobre determinado esporte, tais como os maiôs da natação, a possibilidade de desconfiar e de imputar no esporte profissional que algo está por detrás dos verdadeiros fatos é enfim uma narrativa interessante que pode lançar uma polêmica, um fato, uma narrativa ${ }^{22}$. Ora, há uma sugestão de que algo obscuro, sujo e quase incompreensível macula, mancha e suja o esporte, um esporte que visto a partir da ótica profissional é corrompido pelo dinheiro e não mais pelas glórias da vitória e da conquista do amadorismo.

Conforme Perera e GLEYse ${ }^{6}$ em seus estudos sobre as categorias de análise de puro, impuro e segredo, definiram que a compreensão sobre o segredo:

$\mathrm{O}$ segredo constitui um terceiro aspecto a ser considerado para apreender o movimento contraditório do "tudo ou nada", do "puro ou impuro". Efetivamente, impuro é muitas vezes associado, no que concerne ao doping, à noção de segredo. Ele oculta possivelmente o impuro dando-lhe a aparência inversa, mas o segredo pode também, como o veremos, transformar o puro em impuro ${ }^{6}$.

Alem disso, a ideia de que as notícias tomam a forma de um vortex como analisou WHANNEL ${ }^{1}$ nos serve para explicitar que os acontecimentos ao se tornarem notícias ganham dimensões espirais e consequentemente crescentes na medida em que o que se fará ao longo do tempo é confirmar ou não algo que precisa ser novamente noticiado, com direito a novas opiniōes, depoimentos até se chegar ao atleta. Em nossas análises percebemos que as reportagens sobre as desconfianças quanto ao desempenho dos (as) atletas tendem a ser fartamente consideradas, mas que de fato nada provam. Ainda.

É só uma questão de tempo e de "vontades", para sabermos onde tudo isto vai dar. Há de se esperar a criação e uso de novas tecnologias controladoras para manchar a reputação de mais gente. Ocasionadas por um ambiente de ampla desconfiança que precede estas conquistas divulgadas pela mídia que nos faz duvidar que para além da carga genética, das condições de treinamento e de que "todos" os esforços dos atletas não existam de fato grandes atuações que abalem o mundo por seus resultados. $\mathrm{E}$ as imensas pressões de todo um ambiente (ex. nações, patrocinadores, economia) para conquistar estes resultados. Este todo ao qual nos referimos é um investimento coletivo no atleta ele não é a tentação, a pílula mágica, ou remédio dos sonhos que é apenas a ponta deste "iceberg" que macula e destrói as carreiras e reputações dos mais fracos desta engrenagem esportiva.

\section{Guerra contra as drogas: vigiar e punir}

Nesse estudo identificamos uma maneira recorrente de tratar o conteúdo das reportagens, nas questóes envolvendo o uso de "doping" nos Jogos Olímpicos de Londres 2012, que se assemelha ao que os aparelhos de controle e repressão do Estado fazem quanto à forma de se tratar o uso de substâncias ilícitas pela sociedade. Como é o caso da guerra às drogas que se estendeu para outros campos sociais, entre eles o esporte. Desde a criação das esferas de controle que visam proibir o uso de substâncias e punir quem desrespeita tais regras percebemos que estas organizaçóes que têm a WADA ${ }^{\mathrm{f}}$ como sua organização principal, acabam por repetir os mesmos procedimentos e as mesmas formas de compreender estas situações, uma delas é vigiar e punir, ou seja, pegando emprestado o título do livro de FoucaulT ${ }^{23}$, inferimos que as organizaçôes esportivas repetem de forma consciente e deliberada a questão policialesca, fortalecendo a ideia de que há apenas uma forma de se tratar deste assunto: proibindo e punindo de forma exemplar.

A WADA está determinada a eliminar das competiçóes todos aqueles atletas que ousarem infringir o Código Mundial "Antidoping” pela utilização de substâncias ou métodos proibidos para aumentar o desempenho no esporte. Esta proibição tende a 
ser encarada como uma guerra declarada, em que o "flagelo" deve ser combatido ${ }^{24-26}$.

O "war on drugs" se estende para "war on doping". Ou seja, palavras como "combate", "manchar", "punido", "trapaceiros" e expressões tais como "guerra às drogas", "mal do esporte", "vencer a qualquer custo" fazem parte do vocabulário do conteúdo destas notícias. A própria palavra usada em nossa língua para os casos de atletas que tem seus resultados dados como positivos demonstra que a questão é de cima para baixo, de controle, quase governamental. Ser "pego" num exame "antidoping" é tomado como uma forma pública de vergonha. Não obstante, a primeira ação do Comitê Olímpico do país do atleta envolvido se antecipa ao Comitê Olímpico Internacional (COI) e o expulsa da Vila Olímpica imediatamente, assim que um exame confirma o resultado de "doping"27.

Além disso, existe também associado à questão de combate ao "doping" uma impressão de que isto acontece corriqueiramente, mas apenas alguns poucos afortunados é que tem sido "pegos" no volume cada vez maior de testes realizados em $\mathrm{JO}^{5}$. Para se ter uma ideia do aumento crescente do controle (repressão) sobre os atletas sabemos que nos JO de Atenas (2004) foram coletados 3600 testes. Nos JO de Beijing (2008) o número saltou para 4500. E em Londres (2012) mais de 5000 testes foram realizados (3.800 de urina e 1200 de sangue) durante os jogos e mais 4.000 foram realizados antes de seu início (cerca de um mês antes), monitorando previamente o uso de substâncias por atletas que representaram seus países nos JOL'. Ao longo dos anos aumentam os investimentos em controles de "doping", porém o número de "atletas positivos" ainda permanece no mesmo patamar ${ }^{28}$.

Por isso a questão é tomada com sentidos de "gravidade", urgência, dando a impressão de que aqueles que utilizam "doping" são em número muito maior do que os 11 casos dos referidos JOL 5 .

Abaixo selecionamos trechos reportagens analisados em seguida:

Faxineiros e funcionários de segurança da Vila Olímpica foram instruídos a espionar atletas como parte dos esforços para combater o doping nos Jogos 2012, segundo informaçôes do jornal britânico The Independent. A ideia, segundo o jornal, é que os faxineiros ou seguranças relatem às autoridades toda vez que encontrarem remédios, comprimidos, equipamento intravenosos ou outros itens suspeitos nas habitaçōes de atletas ${ }^{29}$ (grifo nosso).

Victor Conte, proprietário do ex-laboratório Balco e culpado em um escândalo global de uso de esteroides, disse nesta quinta-feira que o programa de testes antidoping da Olimpíada 2012 é irrelevante ${ }^{30}$ (grifo nosso).

O combate ao doping na véspera da Olimpíada de Londres tem sido bem-sucedido, já que nos últimos meses os testes flagraram mais de 100 atletas usando drogas que melhoram o desempenho, disse o presidente do Comitê Olímpico Internacional (COI), Jacques Rogge, nesta sexta-feira. Horas antes da cerimônia de abertura dos Jogos 2012, Rogge afirmou que os esforços do COI para ter uma Olimpíada limpa estão dando frutos ${ }^{31}$ (grifo nosso).

As matérias se assemelham com a pesquisa de $\mathrm{ME}$ DEIROS e SANTOS $^{3}$ em relação ao discurso midiático de que a existência de um esporte "limpo" é coisa do passado e o que se espera é que sejam aperfeiçoados os mecanismos de controle de detecção e de um código de ética eficiente que seja capaz de punir e a partir destas punições seja inibido o uso destas substâncias pelos demais.

Não há mais amadores apaixonados pelo que fazem, existem sim profissionais bem pagos que estão segundo a nossa interpretação a pagar o preço necessário para alcançar o lugar mais alto no pódio.

Diferente dos estudos sobre "doping" na mídia que focam em usuários que frequentam academias de ginástica, utilizando as chamadas "bombas" e que tem como referências os danos à saúde dos indivíduos, as matérias jornalísticas no período olímpico coletado focam claramente na questão da vitória a qualquer custo, ou seja, na personificação daquele atleta que usa o "doping" e que esta preocupado em burlar uma regra e acaba consequentemente sujando seu nome, seu país e seu esporte ${ }^{2}$.

É provável que os escassos resultados de "doping" encontrados nos JOL sejam fruto dos poucos atletas desavisados mais vulneráveis por questões estruturais (ex. carência de apoio médico e laboratorial, máorientação, o uso de substância ou método ultrapassado). Aqueles que consequentemente acabaram expostos às sanções dos seus resultados positivos. Outra possibilidade que não pode ser descartada esta relacionada aos problemas causados pelos testes que dão resultados "falso-positivos"

Apesar dos esforços dispendidos na tentativa de controlar o "doping" e possibilitar o "equilíbrio" de condiçôes entre os atletas, existem ainda muitas outras maneiras de desequilibrar o jogo que são amplamente praticadas pelos atletas de mais recursos (pouco questionadas até o momento). Por exemplo: formas de treinamento como o estímulo 
elétrico muscular (adaptadas de materiais para uso espacial), as simulaçõos do treinamento de altitude (com câmeras hiperbáricas), ou o uso de tênis que contém alta tecnologia para sua fabricação expõem o quanto são injustas e desequilibradas as diferenças entre atletas que podem ou não ter condições ideais de treinamento acesso a essas facilidades. Além disso, há o conhecido "doping" genético que é ainda difícil de detectar. Estes exemplos de desigualdade tecnológica e econômica entre os atletas tornam o "fair play" tão almejado pelas organizações esportivas do mundo no mínimo discutível ${ }^{28}$.

Consideramos que as narrativas encontradas no conteúdo midiático pesquisado se aproximam das falas encontradas nas entidades e autoridades que controlaram "antidoping" no esporte olímpico.

Ao aprofundarmos nossas análises nas reportagens feitas durante os Jogos Olímpicos de Londres 2012 observamos que as reportagens criavam um tom condenatório, focado inicialmente na figura pessoal do atleta, posteriormente na modalidade esportiva (casos de modalidades que estão associadas ao uso frequente de "doping" como o atletismo e o ciclismo) e por último e não menos importante no país no qual este atleta representa (tais como organizaçóes esportivas de países que parecem negligenciar o estado geral de saúde de seus atletas).

Compreendemos que quanto mais grandioso for o recorde, a conquista realizada, maior será a possibilidade deste (a) atleta ser questionado (a), até mesmo com perguntas relacionadas à temática do "doping", mesmo que seu nome, sua trajetória esportiva não tenham tido até o momento nenhuma relação com este assunto. Citamos como exemplo às questôes feitas por uma revista de grande circulação semanal que entrevistou o atleta Usain Bolt ${ }^{32 h}$.

O estudo constatou que há a ausência de discussões sobre o uso de substâncias proibidas nas questôes relacionadas à saúde dos atletas tanto no momento presente quanto no futuro. Focam-se no "flagrante", na desconfiança e no ceticismo relacionando o rendimento dos atletas ao provável uso de substâncias e métodos indetectáveis que ainda é claro não foram descobertos. Culpabilizar o atleta tem sido o caminho mais fácil encontrado pelos meios de comunicação para demostrar o problema. É claro que o atleta deve ser responsável pelo seu corpo e que em última instância precisa saber tudo o que ingere. Porém existe nesse meio esportivo outros corresponsáveis treinadores, equipes médicas e donos de laboratório que também deveriam contrair esse ônus do "doping" ao prescrever ou orientar o uso de medicamentos, de suplementos (produtos contaminados) e de outras práticas proibidas (ex. "doping" genético) de forma intencional ou não. Mostramos em nossa investigação que a visão estreita e simplista pode não contribuir para as redes de interesse e de controle que se estabelecem no esporte de alto nível; sobretudo, das federações, dos técnicos, das equipes médicas e porque não dos órgãos de controle quando distribuem seus comunicados dizendo que não há nada contra determinado atleta.

Aliás, discussōes na mídia sobre a Redução de Danos $^{5}$ mesmo que ainda raras, por vezes são debatidas na questão dos usuários de drogas parecem ser praticamente fora de discussão quando entram no campo esportivo, visto que o atleta esportivo está em outra categoria de aceitação, aquela que se aproxima do role model, do ídolo, tal como visto em HelaL ${ }^{19}$.

Seria o atleta pego um trapaceiro, uma pessoa que deve ser punida e que diferente do usuário de anabolizantes de academia ${ }^{33}$ não faz o uso de anabólicos (“doping”) em prejuízo próprio, mas em prejuízo dos outros que estão na mesma competição, buscando atingir a vitória e o recorde? Porque o atleta se transformaria em um trapaceiro e deixaria o "fair play" como uma idealização distante do fato concreto?

Por qual razão, as marcas que duram há muito tempo tendem a ser tratadas com mais ceticismo e os atletas que conseguem tais feitos tendem a entrar no radar da mídia numa mistura entre glorificação por seus feitos e desconfiança pelo que realizam?

Porque não existem atletas que possam atualmente alcançar os recordes do passado? Fica aqui uma série de questionamentos, suspeita de que tais marcas só podem ter sido obtidas com a ajuda de substâncias proibidas.

Contra a corrente da evolução técnica, alguns recordes expressivos - principalmente no atletismo - permanecem intocáveis por décadas. Casos, por exemplo, dos $100 \mathrm{~m}$ rasos feminino, cravados em 10,54 s em 1988 pela americana Florence GriffithJoyner e jamais superados, e dos $400 \mathrm{~m}$ rasos, em 43,18 s, de Michael Johnson (1999). Nos saltos, então, a maioria dos recordes parece inalcançável: no salto com vara, ninguém chega perto dos $6,14 \mathrm{~m}$ do ucraniano Sergey Bubka, de 1994, e a russa Yelena Isinbayeva é a única a superar os $5 \mathrm{~m}$ no feminino. No salto em altura, o cubano Javier Sotomayor desde 1993 é o recordista, com 2,45 m. - Hoje, o controle sobre os atletas é maior, há a questão do doping. Só se aparecesse um Bolt no salto - avalia o técnico de saltos Alexandre Coelho ${ }^{34}$ (grifo nosso). 
Estudos futuros podem contribuir para a discussão do "doping" esportivo para além dos tons de repressão, controle, desconfianças, para uma abordagem mais argumentativa com enfoque na saúde coletiva e nos processos de tomadas de decisões individuais do atleta sobre o seu próprio corpo.
Portanto, a pergunta final que pode ser feita é: estamos de fato sendo pautados pela mistura entre admiração e desconfiança quando assistimos os melhores atletas do mundo atuando em JO?

\section{Notas}

a. Possession by an Athlete of a Prohibited Substance or a Prohibited Method, unless the Athlete establishes that the Possession is pursuant to a therapeutic use exemption ("TUE") granted in accordance with Article 3.2 (Therapeutic Use) or other acceptable justification. Em tradução livre: Posse de substância proibida pelo atleta ou um método proibido, exceções aos casos de uso terapêutico em conformidade ao artigo 3.2 do presente Código ou uma justificativa aceitável. [citado 17 dez. 2012]. Disponível em: http://www.wada-ama.org/Documents/News_Center/News/2011/IOC_Anti-Doping_Rules_London_2012_EN.pdf.

b. ALEXA- The Web Information Company. [citado 13 dez. 2012]. Disponível em: http://www.alexa.com.

c. Cf.http://g1.globo.com/mundo/noticia/2012/07/suspeita-de-doping-de-nadadora-causa-indignacao-na-china.html.

d. Cf. http://g1.globo.com/mundo/noticia/2012/08/londres-se-despede-dos-jogos-eua-lideram-nas-medalhas.html.

e. Cf.http://extra.globo.com/esporte/ciclista-hamilton-perde-ouro-de-atenas-por-doping-8-anos-depois-5756263. html\#ixzz28IA5vV5A.

f. Foi concebida em 10 de novembro de 1999 a Agência Mundial de Antidoping AMA ou WADA (sigla em inglês), órgão regulador dos esportes olímpicos. Esta agência tem como objetivo principal liderar uma campanha global para que o esporte seja praticado livre do doping. World Antidoping Agency. [citado 17 dez. 2012]. Disponível em: http://wada-ama.org/. g. Cf. [citado 13 dez. 2012]. Disponível em: http://www.olympic.org/london-2012-news.

h. Em sua entrevista dada ao periódico semanal Veja, o atleta Usain Bolt respondeu a três perguntas diretas sobre o uso de drogas e uma indireta: a primeira sobre a questão do doping no atletismo jamaicano, a segunda sobre sua opinião sobre o ciclista Lance Armstrong (banido do esporte) e a terceira relacionada sobre sua capacidade de perceber se algum de seus adversários estaria usando substância proibidas. A quarta pergunta está relacionada ao fato de que a ingestão de certos alimentos presentes nos hábitos alimentares seriam possíveis de oferecer melhores rendimentos esportivos ${ }^{32}$.

\section{Abstract}

The media coverage about doping in London 2012 Olympic Games: the case of G1 website

The issues about doping are frequently in media, mainly during sports mega events such as Olympic Games. Famous athletes like Ben Johnson (Seoul 1988) and Marion Jones (Sydney 2000) were banished by sports organizations, and their career had declined forever. This research aims to study news about doping in an important Brazilian news website during London 2012 Olympic Games, named G1. In so doing that, all the news were selected and categorized from July 25 to August 132012 by the following key words: doping and London 2012 Olympic Games. One hundred and ninety one news were identified, but only 145 were related to Olympic Games. Fifty four were found in the website newspaper called "Extra Online", 37 in "Globo Esporte", 23 in "G1", 22 in "0 Globo" and 9 in "Época" magazine. The theoretical reference chosen to read news carefully and deeply was the Content Analysis. Two categories emerged from analysis: a) the doubts about the high sport performance of some athletes; $b$ ) the necessary punishments to "positive athlete exams". The conclusions point out that media treats athletes like cheaters. It also identifies World Antidoping Agency (WADA) as an "international police" in a permanent fight against doping. This kind of thoughts is very similar to war against drugs, and it makes all the efforts to control athletes and their performances.

KEY WORDS: Doping; Sports; Press; Athletes. 


\section{Referências}

1. Whannel G. Media sport stars: masculinities and moralities. Londres: Routledge; 2002.

2. Maluly L. O doping e a cobertura jornalística no Brasil. In: Marques JC, organizador. Comunicação e esporte: diálogos possíveis. São Paulo: Artcolor; 2007. v.1, p. 136-49.

3. Medeiros A, Santos D. O doping no discurso midiático. Motrivivência. 2008;20.

4. Souza ECA, Queiroz KFS, Azevedo PCS, Zanlorenzi TD, Titski ACK. Rebeca Gusmão: vigiada, punida e examinada. $1^{\circ}$ ENCONTRO da Associasson Latinoamericana de Estudios Socioculturales del Esporte (ALESDE). "Esporte na América Latina: atualidade e perspectivas”, Universidade Federal do Paraná - Curitiba - Paraná - Brasil, 30, 31/10 e 01/11/2008.

5. Kayser B, Broers B. The Olympics and harm reduction? Harm Reduction J. 2012, 9:33. [citado 7 dez 2012]. Disponível em: http://www.harmreductionjournal.com/content/9/1/33.

6. Perera E, Gleyse J. O doping ao longo do século XX na França: representações do puro, do impuro e do segredo. Rev Bras Cienc Esporte. 2005;27:55-74.

7. Wolf M. Teorias da comunicação. Tradução de Maria Jorge Vilar de Figueiredo. Lisboa: Editorial Presença; 1995.

8. Tannen D. The argument culture: stopping America’s war of words. New York: Ballantine; 1998.

9. Minayo MC. O desafio do conhecimento: pesquisa qualitativa em saúde. São Paulo/Rio de Janeiro: Hucitec-Abrasco; 2008.

10. Borelli V. O esporte como uma construção específica no campo jornalístico. 25 Congresso Anual em Ciência da Comunicação; 2002; Salvador, BA. Salvador: INTERCOM; 2002.

11. Extra. Londres 2012: COI confirma exclusão de atleta da Albânia por doping. [citado 20 ago 2012]. Disponível em: http://extra.globo.com/esporte/londres-2012/londres-2012-coi-confirma-exclusao-de-atleta-da-albania-por-doping-5614408.html\#ixzz2K7utxG3E.

12. Extra. Reuters. Velocista são-cristovense é eliminada por admitir uso de droga. [citado 20 ago 2012]. Disponível em: http:// extra.globo.com/esporte/velocista-sao-cristovense-eliminada-por-admitir-uso-de-droga-5621499.html\#ixzz2K7vwP1Rs.

13. Extra. Reuters. Corredor marroquino Laalou é flagrado no doping. [citado 20 ago 2012]. Disponível em: http://extra. globo.com/esporte/corredor-marroquino-laalou-flagrado-no-doping-5681293.html.

14. Globo Esporte. Ciclista russa é expulsa dos Jogos Olímpicos de Londres por doping. [citado 20 ago 2012]. Disponível em:<http://globoesporte.globo.com/olimpiadas/noticia/2012/08/ciclista-russa-e-expulsa-dos-jogos-olimpicos-delondres-por-doping.html.

15. Extra. Reuters. Italiano campeão olímpico de marcha é excluído da Olimpíada por doping. [citado 20 ago 2012]. Dis-ponível em: http://extra.globo.com/esporte/italiano-campeao-olimpico-de-marcha-excluido-da-olimpiada-pordoping-5705640.html\#ixzz28I8rzIc1.

16. Extra. Reuters. Corredora síria é 11a atleta banida dos Jogos por doping. [citado 25 ago 2012]. Disponível em: http:// extra.globo.com/esporte/corredora-siria-11a-atleta-banida-dos-jogos-por-doping-5763286.html\#ixzz28IBSdAtQ.

17. G1. Reuters. Londres tem terceiro caso de doping em dois dias. [citado 20 ago 2012]. Disponível em: http://g1.globo. $\mathrm{com} / \mathrm{mundo} /$ noticia/2012/07/londres-tem-terceiro-caso-de-doping-em-dois-dias.html.

18. Globo Esporte. Agências de Notícias de Londres. IAAF confirma nove punições por doping às vésperas das Olimpíadas. [citado 20 ago 2012]. Disponível em: http://globoesporte.globo.com/olimpiadas/noticia/2012/07/iaaf-confirma-novepunicoes-por-doping-vesperas-das-olimpiadas.html.

19. Helal R. Campo dos sonhos: esporte e identidade cultural. Comunicação Mov Mídia Educ Fís. 2000;3:70-81.

20. G1. Reuters. Londres se despede dos Jogos; EUA lideram nas medalhas. [citado 20 ago 2012]. Disponível em: http:// g1.globo.com/mundo/noticia/2012/08/londres-se-despede-dos-jogos-eua-lideram-nas-medalhas.html.

21. Revista Época. Um campeão que ressuscitou uma modalidade. [citado 20 ago 2012]. Disponível em: http://revistaepoca.globo.com/Sociedade/olimpiada2012/noticia/2012/08/um-campeao-que-ressuscitou-uma-modalidade.html.

22. Lovisolo H. Mídia, lazer e tédio. Rev Bras Ciênc Comun. 2002;25:43-66.

23. Foucault M. Vigiar e punir: nascimento da prisão. Petrópolis: Vozes; 1987.

24. Simon R. Fair play: sports, values, and society. Boulder: Westview Press; 1991.

25. Loland S. Fair play in sport: a moral norm system. London: Routledge; 2002.

26. Fiore M. O lugar do estado na questão da droga: o paradigma proibicionista e as alternativas. Rev Novos Estudos. 2012:92.

27. Extra. Londres 2012: chefe da missão, Bernard repudia doping de Kyssia: 'cada um tem sua res-ponsabilidade'. [citado 20 ago 2012]. Disponível em: http://extra.globo.com/esporte/londres-2012/londres-2012-chefe-da-missao-bernardrepudia-doping-de-kyssia-cada-um-tem-sua-responsabilidade-5691256.html\#ixzz28I4tCFYb. 
28. Kayser B, Mauron A, Miah A. Current anti-doping policy: a critical appraisal. BMC Med Etnics. 2007;8:2. [citado 25 fev. 2011]. Disponível em: http://biomedcentral.com/1472-6939/8/2.

29. G1. BBC. Faxineiros da Vila Olímpica recrutados para 'espionar' atletas. [citado 20 ago 2012]. Disponível em: http:// g1.globo.com/mundo/noticia/2012/07/faxineiros-da-vila-olimpica-recrutados-para-espionar-atletas.html.

30. Extra. Reuters. Usuários de doping enganam fácil, diz dono de laboratório. [citado 20 ago 2012]. Disponível em: http:// extra.globo.com/esporte/usuarios-de-doping-enganam-facil-diz-dono-de-laboratorio-5740176.html\#ixzz28I9J2Oj9.

31. Extra. Reuters. Combate ao doping está funcionando, diz presidente do COI. [citado 20 ago 2012]. Disponível em: http:// extra.globo.com/esporte/combate-ao-doping-esta-funcionando-diz-presidente-do-coi-5603561.html\#ixzz28SvnjkPF.

32.Veja. Usain Bolt: Entrevista com a lenda viva do esporte mundial. [citado 10 nov. 2012]. Disponível em: http://veja. abril.com.br/blog/ricardo-setti/tema-livre/usain-bolt-fala-a-lenda-viva-do-esporte/. (Coluna do Ricardo Setti).

33. Da Silva PRP, Machado Junior LC, Figueiredo VC, Cioffi AP, Prestes MC, Czepielewski MA. Prevalência do uso de agentes anabólicos em praticantes de musculação de Porto Alegre. Arq Bras Endocrinol Metab. 2007; 51:104-10.

34. Extra. Reduzidos a pó: mais de 25 recordes mundiais foram quebrados em Londres. [citado 15 nov. 2012]. Disponível em: http://extra.globo.com/esporte/londres-2012/reduzidos-po-mais-de-25-recordes-mundiais-foram-quebrados-emlondres-5761222.html\#ixzz28IBwdr27.

\begin{tabular}{r|r} 
ENDEREço & \\
Paulo Rodrigo Pedroso da Silva & \\
Universidade Gama Filho & \\
Programa de Pós-Graduação Strictu-Sensu & \\
em Ciências do Exercício e do Esporte & Recebido para publicação: 07/02/2013 \\
R. Manoel Vitorino, 553 - Piedade & Revisado: 15/04/2013 \\
20740-280 - Rio de Janeiro - RJ - BRASIL & Aceito: 14/05/2013 \\
e-mail: rodrigomettrica@gmail.com & \\
&
\end{tabular}

